TITLE:

$<$ Article> Branch-Drop Disp11ty of a Female Chimpanzee (Pan troglodytes troglodytes) of Petit Loango, Gabon.

AUTHOR(S):

CITATION:

$<$ Article> Branch-Drop Displity of a Female Chimpanzee (Pan

troglodytes troglodytes) of Petit Loango, Gabon.. Pan Africa News 1998, 5(2): 15-16

ISSUE DATE:

1998-12

URL:

http://hdl.handle.net/2433/143373

RIGHT:

Copyright (c) Pan Africa News. 


\title{
<ARTICLE> \\ Branch-Drop Display of a Female Chimpanzee (Pan troglodytes troglodytes) of Petit Loango, Gabon.
}

\author{
Yuji Takenoshita, Juichi Yamagiwa \\ and Toshisada Nishida \\ Laboratory of Human Evolution Studies, \\ Kyoto University
}

Scientific research of great apes by the Kyoto University team at Petit Loango, Gabon, has continued for 4 years since 1994 (1). On October 19, 1998, it continued to rain from 07:30 to $13: 30$, and we recorded $128 \mathrm{~mm}$ of precipitation during the period Around 14:30, we headed for a forest where on October 16. we had seen a lot of fresh mango remains left by apes and monkeys. When we arrived, we again found fresh mango remains and fresh beds where the chimpanzees had slept in the previous night.

At $15: 42$, we suddenly noticed a chimpanzee moving quickly high above as we walked past the edge of a mango grove. It was an early adolescent female, and soon a past-prime adult female with a white back slid down a big tree and fled on the ground.

Meanwhile, the adolescent female returned and proceeded to a huge kapok tree (Ceiba pentandula), followed by a white-backed adult female and a small juvenile. The adult female, who was suspected to be the mother of both the adolescent and the juvenile, remained at the large bough of the kapok tree even after her suspected offspring disappeared. She repeatedly called out in a frenzy "Wrrah". At 15:44, she forcibly stamped on the branch just before the fifth "Wrrah" call.

At 15:45, a smaller mother with an infant under her belly approached the female. At $15: 46$, two adult females called "Wrrah" in unison although they were $10 \mathrm{~m}$ apart. At 15:48, the mother-infant joined the white-backed female in the kapok tree. Two females called out together again and the older female slapped a tree trunk with one hand when she called.

At 15:49, an elephant emerged. The 


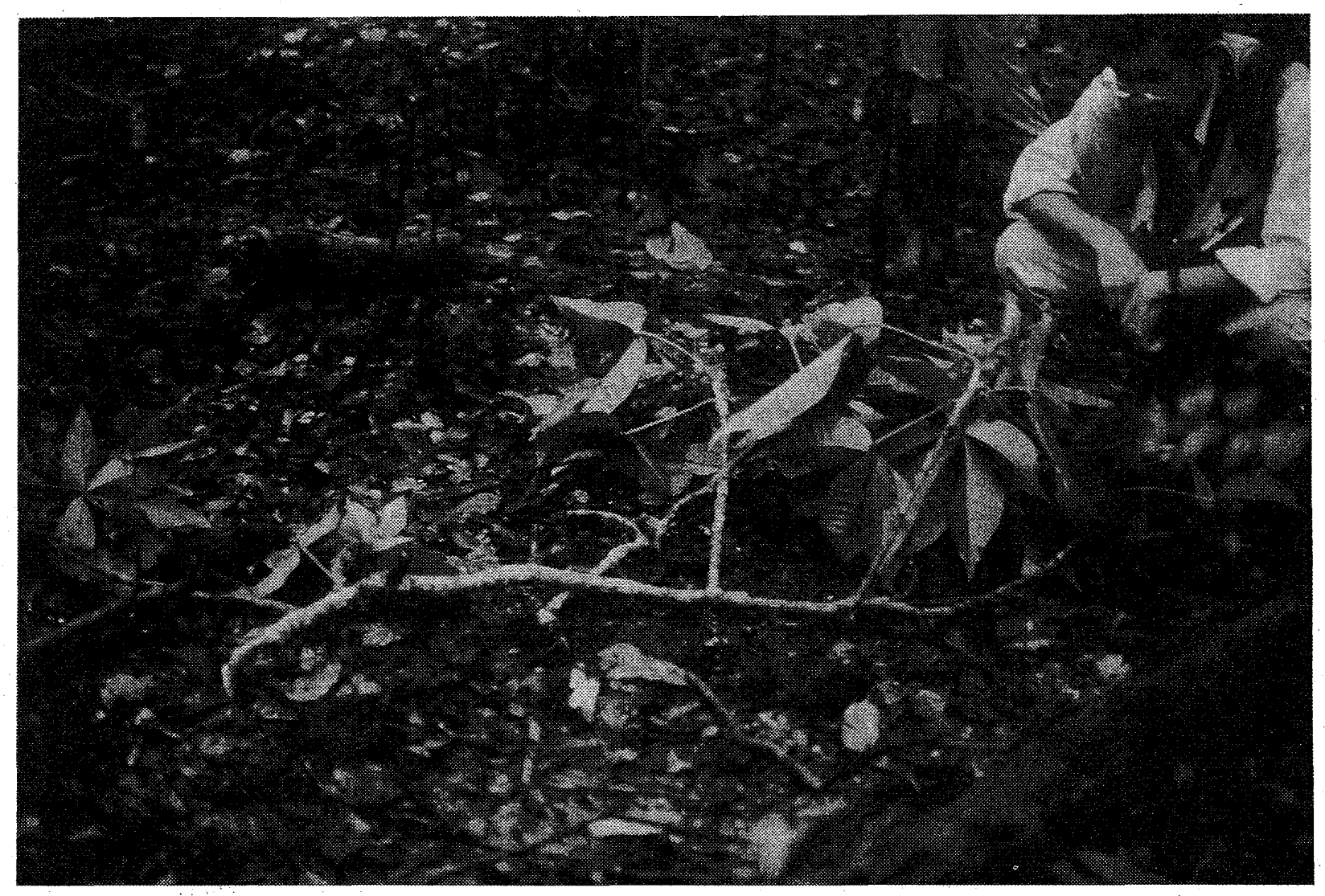

Fig. 1 The branch dropped by a female chimpanzee

smaller female appeared relaxed, but the older female scratched herself vigorously, showing uneasiness towards our presence, the elephant's or both of us. Subsequently, the smaller female with her infant brachiated to the tip of the bough and moved to another tree. Between 15:50 and 15:53, the older female called out 6 times while leaping, climbing, or sitting. At 15:53, we heard her "Wrrah" call and a slapping sound from where the female was sitting. The elephant came closer to us, and we retreated a bit. The female appeared to be eating the unripe fruits of the kapok.

At 15:56, the female suddenly moved and broke a large branch with her right arm and dropped it to the ground where it fell within $2 \mathrm{~m}$ of us. The branch was $3.5 \mathrm{~cm}$ in diameter and 150 cm long (Fig. 1). At 16:06, she threw a branch down a third time, and continued to call "Wrrah" until 16:08 when she followed her companions. At 16:09, she climbed down the tree and finally fled.

In conclusion, we observed chimpanzees. for 20 minutes. The adult female called "Wrrah" 34 times. She appeared to show a feint so that her offspring would move away from us. She displayed intimidation behavior such as <slap >, $<$ stamp >, <"Wrrah" call $>$, and <break and drop a branch $>$ to frighten the human observers. It is interesting to ask whether <break and drop a branch $>$ by an adult female is common among central African chimpanzees because TN has never seen female chimpanzees of Mahale, east Africa, display this behavior (2). This study was conducted under the Monbusho International Scientific Research Program (\#08041146 to J. Yamagiwa).

\section{REFERENCES}

(1) Yamagiwa J. , Angoue-Ovono, S. \& Kasisi R. 1995. Densities of apes' food trees and primates in the Petit Loango Reserve, Gabon. Afr. Study Monographs 16:181-193.

(2) Nishida T., Kano, T., Goodall, J., McGrew W.C. \& Nakamura M. (submitted) Ethogram and ethnography of Mahale chimpanzees. Anthrop. Sci. 